\title{
Prática Pedagógica e Mídias Digitais: um Diálogo Necessário na Educação Contemporânea
}

\section{Pedagogical Practice and Digital Media: a Necessary Dialogue in Contemporary Education}

\author{
Rosilene Maria Tessari ${ }^{\mathrm{a}}$ Cleonice Terezinha Fernandes*a; ${ }^{*}$ Maria das Graças Campos ${ }^{\mathrm{a}}$
}

aUniversidade de Cuiabá, Programa de Pós-Graduação Stricto Sensu em Ensino. MT, Brasil.

*E-mail: cleo_terezinha@hotmail.com

\begin{abstract}
Resumo
Apesar de os avanços científicos e tecnológicos se fazerem, constantemente, presentes nas mais diversas áreas, atualmente, a prática metodológica aponta indícios de poucas transformações no que se refere ao planejamento e aplicação dos conteúdos nas aulas. Este artigo se originou de uma pesquisa qualitativa etnográfica, que discute a importância da contextualização da prática pedagógica perante os desafios impostos pelo avanço tecnológico. O objetivo do estudo é refletir sobre os procedimentos de ensino utilizados por professores de uma escola públic a, apresentando um breve recorte histórico sobre o uso das mídias na escolarização, considerando a evolução tecnológica e o surgimento de diferentes recursos educacionais. A recolha das informações ocorreu pela análise documental e entrevistas semiestruturadas, com a observação de a tividades desenvolvidas. Os resultados apresentam aulas expositivas e a utilização do livro didático e do quadro como ferramentas mais empregadas pelos professores em suas aulas. A conclusão aponta para a importância das discussões sobre os temas no panorama educativo contemporâneo e destaca a necessidade de o professor procurar se atualizar, modernizando seu ofício no contexto atual, garantindo o uso das tecnologias como instrumento capaz de priorizar seu desenvolvimento e do seu educando, promovendo a aplicação das Tecnologias Digitais de Informação e Comunicação na conjuntura de um processo de ensino e aprendizagem dinâmico, significativo e transformador.
\end{abstract}

Palavras-chave: Educação. Tecnologia. Professores. Ensino e Aprendizagem. Formação continuada.

\begin{abstract}
Although technological evolution is constantly present in the most diverse areas today, methodological practice points to evidence of few changes in relation to the content planning and application in classes. This article originated from a qualitative ethnographic research that discusses the importance of contextualizing pedagogical practice before the challenges imposed by technological advances. The objective of the study is to reflect on the teaching procedures used by teachers of a public school, presenting a brief history of the use of media in schooling, considering the technological evolution and the emergence of different educational resources. The information collection was based on documentary analysis and semi-structured interviews, with observation of the activities developed. The results indicate expository classes and the textbook use and the blackboard as tools most used by teachers in their classes. The conclusion points to the importance of discussions on topics in the contemporary educational landscape and highlights the need for teachers to seek to update themselves, modernizing their practice in the current context and highlighting the use of technologies in order to prioritize their development and that of the students, promoting the application of Digital Information and Communication Technologies in the context of a dynamic, meaningful and transforming teaching and learning process.
\end{abstract}

Keywords: Education. Technology. Teachers. Teaching-Learning. Continuing education.

\section{Introdução}

A educação formal no Brasil, assim como no restante do Mundo, passou por transformações variadas durante seus diversos momentos. Desde o período colonial brasileiro, com a implantação dos métodos jesuíticos de ensino formalizado até as mais recentes e modernas tendências pedagógicas, a utilização das ferramentas e dos recursos metodológicos aplicados ao ensino vem sendo discutida, na esfera educacional, como um tema basilar para o sucesso no processo educativo formalizado.

A prática pedagógica é, sem dúvida, o principal elemento de ligação entre o educando e o conhecimento sistematizado pela Instituição Escolar. Deve-se enfatizar, entretanto, que o processo de escolarização não compreende todo o grau de desenvolvimento intelectivo que o indivíduo pode alcançar ao longo de sua trajetória.
O conhecimento, conforme Piaget (2001), surge da interação entre sujeito e objeto, em um processo inteligente de assimilação, de conscientização, de reflexão e de ação sobre o objeto. De acordo com o autor, a ação de aprender é um processo consecutivo e dinâmico originado dessa interação entre sujeito, meio e objeto. Nessa perspectiva, o aluno não pode mais ser considerado mero espectador e nem o professor deve ser visto como um transmissor de saberes a serem adquiridos, mas sim um orientador da aprendizagem, que se processa através de estágios cognitivos evolutivos e das analogias que o educando estabelece com todas as formas de conhecimento na totalidade de suas relações com os diversos contextos.

Vive-se em um tempo de crescentes e de aceleradas conexões intercontinentais, em que as mídias evoluem constantemente. Junto com este processo, a humanidade 
vivencia uma forte onda de globalização das mídias e do consumo dessas tecnologias. Atualmente, a maioria dos estudantes já inicia seu percurso escolar familiarizados com toda essa modernidade, inclusive, inseridos na comunicação virtual, conectados às diferentes e variadas possibilidades de interação, de cultura, de informação e de produção de conhecimento. Cada vez mais, portanto, torna-se mais difícil prender a atenção dos educandos por meio de aulas expositivas, totalmente feitas do conjunto lousa/professor/aluno.

Embora a disposição de variados recursos tenha aumentado, consideravelmente, em relação à tecnologia e ao acesso à informação, existe ainda uma resistência muito grande por parte de alguns professores, que insistem em acreditar que o quadro e o livro didático ainda são as melhores, ou únicas formas de organizar o conhecimento formal que o currículo escolar exige que seja repassado aos alunos. Portanto, precisa-se delinear um novo horizonte metodológico na prática docente, à luz dos novos paradigmas educacionais e tecnológicos que caracterizam a educação contemporânea. Para isso, é necessário investigar de que maneira esses profissionais relacionam sua prática diária com as experiências que adquirem diante das inovações que, atualmente, se configuram no universo educacional tecnológico?

Frente aos diagnósticos de indisciplina e desinteresse com a aprendizagem, por parte dos educandos, e da constatação do infrequente uso das tecnologias digitais na metodologia aplicada pelos professores colaboradores nesta pesquisa, surgem as primeiras reflexões acerca da necessidade de serem reavaliados os procedimentos adotados pela equipe em relação à utilização desses recursos tecnológicos. Acredita-se que sua inclusão nos procedimentos de ensino pode torná-los excelentes aliados no controle da indisciplina e no combate ao desinteresse dos estudantes pela sua aprendizagem.

Diante do exposto, a pesquisa se orienta pela abordagem qualitativa, com o acompanhamento de algumas atividades realizadas pelos professores, que atuam na E. E. Alice Fontes Pinheiro, em Cuiabá, Mato Grosso. As técnicas para a recolha dos dados ocorreram pelas entrevistas e observação das atividades, assim como a análise do Projeto Político Pedagógico da referida instituição. As discussões estão organizadas a partir da análise documental e das entrevistas realizadas na Unidade Escolar entre os anos de 2018 e 2020, estabelecendo parâmetros comparativos a respeito da utilização dos recursos pedagógicos aplicados na metodologia aplicada pelos parceiros na pesquisa e a evolução das mídias educativas no cenário da educação brasileira.

$\mathrm{Na}$ sequência, as reflexões giram em torno das relações entre a prática educativa e as Mídias Digitais, destacando a prioridade na reorganização da dimensão metodológica na intencionalidade de aprimorar e inovar a prática pedagógica. Por último, as conclusões evidenciam a importância da utilização de variados recursos didáticos e das múltiplas plataformas de aprendizagem, que as tecnologias disponibilizam, visando promover uma aprendizagem mais dinâmica, colaborativa e contextualizada.

Nesse contexto, o objetivo do estudo é proporcionar oportunidades de análise e de reflexão sobre as técnicas metodológicas utilizadas pelos professores parceiros na pesquisa, mais especificamente, no que diz respeito à utilização dos recursos digitais e das tecnologias da informação, na perspectiva de serem evidenciadas práticas, que permitam o entendimento de um fazer docente mediado pela tecnologia contemporânea.

\section{Material e Métodos}

A educação, como um fenômeno social, insere-se no campo das pesquisas sociais como uma vasta rede de analogias que envolvem a subjetividade dos sujeitos, seus pensamentos, suas concepções e ideias construídas pelas relações estabelecidas.

Frente ao caráter subjetivo inerente às relações educativas, e em função da natureza aplicada dessa pesquisa, a abordagem qualitativa é intrínseca ao processo, pois conforme Minayo (2014), a realidade escolar apresenta relações de subjetividade, que não permitem uma análise apenas sob o viés quantitativo. Dessa forma, o estudo é qualitativo, ancorandose no procedimento dedutivo, que segundo Gil (2019), pode facilitar a explicação dos argumentos em consonância com os critérios de análise dos dados coletados, na perspectiva de orientar logicamente as conclusões. Conforme André (2013, p. 41), a associação dessa qualidade de pesquisa à realidade educativa: "permite reconstituir os processos e as relações que configuram a experiência escolar diária", especialmente, pela possibilidade de aproximação do investigador com a situação pesquisada.

No caso deste estudo, foram usados como instrumentos na produção de informações a análise de documentos, planejamentos de aulas, entrevistas semiestruturadas e a observação das atividades desenvolvidas. As entrevistas, conforme Lakatos (2017), proporcionam benefícios quanto às possibilidades na explicação dos assuntos e facilitam a observação e a avaliação das ações e reações dos pesquisados no que concerne aos assuntos discutidos.

Os educadores parceiros nesta pesquisa são 15 professores, que atuam na E.E. Prof. a Alice Fontes Pinheiro, em CuiabáMT. A escola compõe a rede estadual de educação e atende alunos do $4^{\circ}$ ao $9^{\circ}$ anos do Ensino Fundamental. Esses profissionais fazem parte do quadro da escola tanto como efetivos ou em regime de contrato temporário. A instituição possui vários recursos tecnológicos, entre esses Laboratório de Informática, lousas digitais e sala de vídeo.

Os procedimentos para análise das informações coletadas seguem o processo da triangulação de dados. Conforme Flick (2009), esse procedimento na análise se constitui em refletir sobre o objeto estudado, a partir de diversos aspectos, facilitando a consistência das argumentações. 


\section{Resultados e Discussão}

Ao longo de sua trajetória, o ser humano constrói seu percurso e seu conhecimento através da interação com o ambiente e com seus pares. A educação formal, entretanto, que é quando o sujeito necessita se apropriar de saberes e técnicas científicos, aplicáveis em determinados contextos específicos, requer o acesso a um ensino mais sistematizado, programado e organizado a partir de parâmetros comuns. É o caso, por exemplo, da organização curricular que rege o ensino e as práticas pedagógicas em um determinado sistema educacional de um país ou nação.

A educação formal brasileira apresentou várias mudanças ao longo da sua evolução no que se refere ao uso de ferramentas educativas (Quadro 1).

Quadro 1 - Evolução dos recursos educativos no Brasil

\begin{tabular}{|c|l|}
\hline Período & \multicolumn{1}{|c|}{ Tecnologias Utilizadas } \\
\hline $\begin{array}{c}\text { Brasil } \\
\text { Colonial }\end{array}$ & $\begin{array}{l}\text { Teatro, festas, disputas, debates, música, dança e } \\
\text { ofícios manuais. }\end{array}$ \\
\hline $\begin{array}{c}\text { Brasil } \\
\text { Imperial }\end{array}$ & Livros, jornais, periódicos, quadro, giz, cadernos. \\
\hline República & $\begin{array}{l}\text { Peças anatômicas, aparelhos de química e física, } \\
\text { mapas, livros, cadernos, quadro negro. }\end{array}$ \\
\hline $\begin{array}{c}\text { Anos } \\
50 / 60\end{array}$ & $\begin{array}{l}\text { Sistema de rádio e cinema educativos, projeções } \\
\text { fixas e animadas, vitrolas, livros, quadro negro, } \\
\text { cadernos, cartilhas. }\end{array}$ \\
\hline $\begin{array}{c}\text { Anos } \\
70 / 80\end{array}$ & $\begin{array}{l}\text { Cartilhas, e livros, cadernos, quadro negro e giz, } \\
\text { mimeógrafos. }\end{array}$ \\
\hline $\begin{array}{c}\text { Anos } \\
90 / 00\end{array}$ & $\begin{array}{l}\text { Cartilhas, livros, cadernos, quadro,retroprojetores, } \\
\text { mimeógrafos, vídeos, computadores, impressoras, } \\
\text { TV e DVD. }\end{array}$ \\
\hline $\begin{array}{c}\text { Anos } \\
10 / 18\end{array}$ & $\begin{array}{l}\text { Livros, cadernos, quadro, vídeos, internet, } \\
\text { computadores, notebooks, tablete, impressoras, } \\
\text { aparelhos multimídias, data show, lousa digital. }\end{array}$ \\
\hline
\end{tabular}

Fonte: dados da pesquisa.

Observa-se a seguir que, nas décadas de 1970 e 1980, o quadro negro e o livro didático se consagraram como recursos quase que absolutos (Quadro 2), segundo pesquisas de Queiroz et. al (2015) com um grupo de educadores, que atuou na época.

Quadro 2 - Recursos tecnológicos utilizados nas décadas de 1970 e 1980

\begin{tabular}{|l|c|}
\hline \multicolumn{1}{|c|}{ Recursos Tecnológicos } & \% \\
\hline Livro Didático & 60 \\
\hline Atividade Extra (atividade xerocada) & 10 \\
\hline Rádio, Televisão e Jornal & 0 \\
\hline Internet & 0 \\
\hline Material Mimeografado & 10 \\
\hline Retroprojetor e Projetor de Slides & 20 \\
\hline Quadro Negro & 100 \\
\hline
\end{tabular}

Fonte: Queiroz et al. (2015).

Com a instituição do ProInfo, na década de 1990, o Governo Federal objetivou difundir a utilização da informática na educação. Gradativamente, foram sendo implantados os Laboratórios de Informática nas escolas, introduzindo também os programas iniciais de formação para inserir os educadores nesse processo (COSTA, 2015).

Os requisitos para a reestruturação do PPP da Escola Alice Fontes Pinheiro, em 2018, exigiam a enumeração de práticas metodológicas diferenciadas para o atendimento do Ensino Fundamental e atividades, que eram realizadas no contexto da Inclusão Digital.

Os dados obtidos (Quadro 3) indicam o percentual de docentes, que desenvolviam as atividades consideradas por eles como diferenciadas sob esse aspecto. A questão buscou identificar quais recursos eram utilizados, sem considerar se esse uso era frequente ou intermitente.

Quadro 3 - Atividades com o uso das tecnologias digitais em 2018

\begin{tabular}{|l|c|}
\hline \multicolumn{1}{|c|}{ Atividades } & \% \\
\hline Leitura de livros digitais & 21,05 \\
\hline Jogos pedagógicos & 21,05 \\
\hline Pesquisas na Internet & 79,89 \\
\hline Filmes de vídeo & 63,15 \\
\hline Uso do áudio & 36,84 \\
\hline Atividades xerocadas ou impressas & 89,47 \\
\hline
\end{tabular}

Fonte: dados da pesquisa.

Os resultados encaminham à constatação de que a predominância das atividades ditas diferenciadas incide sobre xerox ou impressão, levando a crer que a questão metodológica ainda reflete a aplicação de atividades prontas, o que consiste apenas na troca do mimeógrafo pela impressora, ou seja, troca-se o aparelho de DVD pelos projetores e o quadro negro ou o livro pela tela do computador. Nenhum dos professores acusou o uso da lousa digital como ferramenta interativa, sendo usada apenas como projetor de filmes e, embora a utilização da internet para pesquisas seja identificada por outra maioria significativa, ainda há que se refletir se essa também não é só mais uma substituição de ferramentas e o método continua o mesmo.

A esse respeito, Brito e Purificação (2011, p. 40) criticam o uso de tecnologias por grande parte dos professores apenas em dados momentos, somente para parecer moderno e inovador, "ou para ter maior segurança, ou para obter status perante os colegas". As autoras consideram que esse uso inadequado acaba transformando esses recursos apenas em "parafernálias eletrônicas", que o docente utiliza como um disfarce aos problemas existentes, e não como um recurso que deve ser adaptado às reais finalidades educativas.

Sob esse enfoque, Soares et al. (2018) destacam a importância de se analisar a questão da simples adoção das tecnologias como um recurso inovador sem a reflexão crítica acerca das didáticas tradicionais, salientando a necessidade da redefinição, no papel do professor, como mediador do conhecimento e não apenas como transmissor. 
No início do ano letivo de 2020, em razão do estudo, procurou-se conhecer especificamente as tecnologias ${ }^{1}$ de ensino mais utilizadas pelos professores participantes em suas aulas.

A solicitação de enumeração para as respostas sugeriu ordem crescente de utilização dos recursos no dia a dia em sala, ou seja, deveriam ser especificados quais recursos eram cotidianamente utilizados em primeiro ou segundo lugares, e assim consecutivamente. Nesse caso, buscou-se identificar quais recursos são usados com maior frequência (Quadro 4).

Quadro 4 - Recursos mais utilizados pelos professores em 2020

\begin{tabular}{|l|c|}
\hline \multicolumn{1}{|c|}{ Recursos mais Utilizados } & \% \\
\hline Livro Didático & 87,50 \\
\hline Computador/Internet & 56,25 \\
\hline Quadro & 87,50 \\
\hline Projetor Multimídia & 75 \\
\hline Impressora & 62,50 \\
\hline TV/DVD & 50 \\
\hline Lousa Digital & 0 \\
\hline Aparelho de som/Áudio & 50 \\
\hline Microfones & 18,75 \\
\hline Caixa de Som & 40 \\
\hline Filmadora & 18,75 \\
\hline Outros/ Celular/Materiais Esportivos & 18,75 \\
\hline
\end{tabular}

Fonte: dados da pesquisa.

De acordo com os dados, pode-se constatar que, diante da comparação com a análise da tabela referente ao período de 1970 e 1980, o quadro e o livro didático se apresentam ainda como as ferramentas metodológicas mais utilizadas pelos profissionais pesquisados.

Nessa atividade, foi solicitado ainda aos educadores que elencassem, por predominância, até três estratégias de aula utilizadas por eles em sala. Automaticamente, diante dos recursos mais utilizados, entre as estratégias metodológicas citadas prevaleceram aulas expositivas, uso do livro e atividades escritas no caderno, seguidas de leitura, debates e seminários.

No que se refere às atividades escritas no caderno pelos alunos, uma análise comparativa temporal entre tais atividades demonstra a padronização, que acompanha as metodologias de ensino, a partir da memorização pela repetição de conceitos e de exercícios prontos (Figura 1).
Figura 1 - Atividades escolares da década de 1950 e da década de 2020

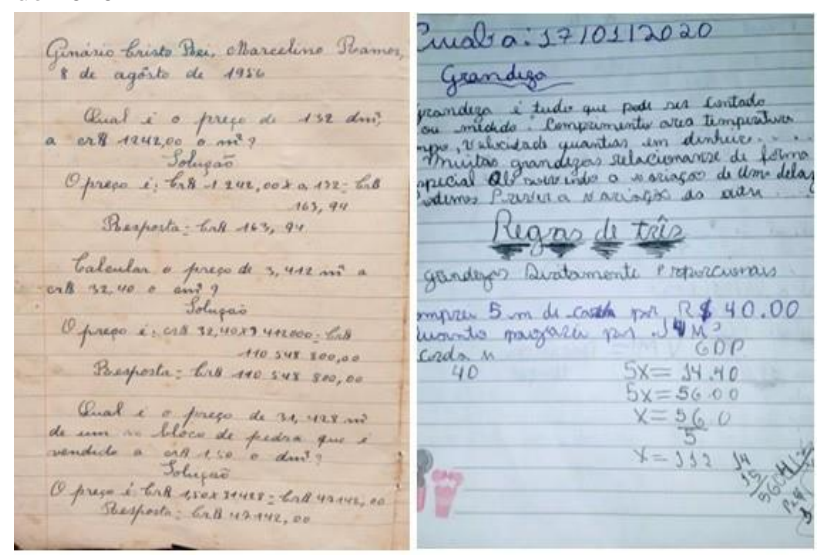

Fonte: os autores.

A figura apresenta atividades de Matemática realizadas com estudantes de escolas públicas. Observa-se um exemplo da década de 1950 e outro atual, do ano de 2020. A primeira atividade foi desenvolvida em 1956, na escola Cristo Rei, em Marcelino Ramos, Rio Grande do Sul, (designada ginásio na época). A série equivalia ao quinto ano. O outro exemplo é de uma atividade aplicada no início do corrente ano letivo, também em escola pública, com alunos do sétimo ano. Considerando-se as diretrizes atuais, que instituíram o Ensino Fundamental em nove anos, organizando-o em Ciclos de Formação e a reforma da grade curricular, é aceitável considerar que os conteúdos sejam correspondentes, conforme a faixa etária dos estudantes.

O exemplo demonstra que, apesar de atualmente os livros apresentarem, explicitamente, os conceitos matemáticos, percebe-se que há ainda a predominância da reprodução pelo estudante no caderno. Além disso, a Web se constitui, no contexto atual, fonte inesgotável de pesquisa que permite aos alunos o acesso às variadas e diversas formas de consulta, em que esses conceitos são abundantemente encontrados.

Embora os modelos exemplifiquem circunstâncias que aludem a aspectos corriqueiros do cotidiano do aluno, permitem constatar que o processo reflexivo necessário, no desenvolvimento dos conceitos abstratos, ainda é pouco valorizado na resolução das questões. Por outro lado, evidenciam a metodologia transmissiva, na qual a aprendizagem pela repetição e memorização é priorizada em detrimento da construção pela descoberta, pela pesquisa e abstração.

A questão metodológica da prática pedagógica é objeto em pauta nas discussões que envolvem a educação sistematizada, principalmente, nos tempos atuais de globalização e de contextos sociais em crescente transformação. Considerando autores como Saviani, que ainda na década de 1980 afirmou: “a educação hoje não pode mais manter-se somente como

1 Nesse sentido, tecnologia se refere a qualquer recurso educativo, segundo as proposições de Kenski (2012, p. 24), como o conjunto de: “[...] conhecimentos e princípios científicos que se aplicam ao planejamento, à construção ou à utilização de um equipamento em um determinado tipo de atividade $[\ldots] "$. 
acadêmica ou profissionalizante, por isso necessitamos de professores que conheçam o sistema produtivo e, principalmente, as inovações tecnológicas" (SAVIANI, 1981, p. 87), pode-se, diante do atual cenário pedagógico e tecnológico, reafirmar essa mesma necessidade.

Os avanços tecnológicos e científicos configuram, na atualidade, particularidades nos modos de vida, que corroboram as transformações estruturais, sociais e econômicas de um novo tempo, caracterizando um novo perfil nas relações sociais e profissionais.

Consequentemente, essas demandas impõem novas exigências às instituições responsáveis pela formação dos educandos, conforme Santos (2006, p.1). Para a autora, "a nova dimensão de sociedade que nos é apresentada hoje, a sociedade digital, clama por novas perspectivas educacionais que envolvam a tecnologia e seus meios na educação".

$\mathrm{Na}$ atual conjuntura, uma escola dinâmica, interessante e motivadora não se sustenta se não adequar seu currículo ao contexto de vida de sua clientela, trazendo para a sala de aula os recursos e meios de aprendizagem, que já fazem parte da vida cotidiana do aluno, mas que lhe é coibido o uso em ambiente escolar em função de fatores que podem e devem ser revistos e reajustados no sentido de promover a aprendizagem significativa e prazerosa. $\mathrm{O}$ uso contextualizado das ferramentas digitais e dos recursos tecnológicos na educação precisa ser refletido, reavaliado e reestruturado para que o aproveitamento metodológico de tais recursos passe de incerto, inerte ou esporádico para um estágio positivo, evolutivo e efetivamente produtivo.

Ainda, na década de 1990, Moran (1995, p.2) refletia sobre o crescente "reencantamento" provocado pelas tecnologias, principalmente, as de comunicação, justamente pela "interação muito mais intensa entre o real e o virtual". $\mathrm{O}$ autor já considerava que esse fator encaminharia a sociedade a uma reorganização de todas as suas dimensões, tanto do econômico ao político quanto do educacional ao familiar.

Em relação à reorganização da dimensão educacional, Cardoso (2015, p. 210) reporta ao fato de que, mesmo em tempos da chamada "explosão científica e tecnológica", a estrutura escolar persiste, com raras adequações, inalterada há décadas, assim como a estruturação das aulas, que seguem ainda a mesma tradição, ou seja, "o professor com um planejamento e/ou cronograma previamente organizado dentro de sua disciplina, exposição do tema e proposição de atividades a serem realizadas junto com os alunos e avaliações". A reflexão da autora remete ao fato de que essa organização persistente e tradicional da escola enseja uma necessidade premente de se voltar olhares mais críticos sobre esse fazer pedagógico.

Refletindo sobre essa assertiva, e tomando o exemplo do uso de multimídias como uma ferramenta educacional, fica claro que a inserção de tecnologias como método eficaz para a aprendizagem está longe de ser uma proposta característica da era digital. Não são recentes as discussões teóricas sobre a utilização desses recursos. As narrativas em conjunto com os recursos audiovisuais, a produção e a criação de vídeos e imagens, as atividades práticas envolvendo ferramentas tecnológicas, já os apresentavam como complemento metodológico ainda antes da atual conjuntura tecnológica. São recursos que poderiam enriquecer e transformar aulas expositivas e extremamente cansativas, tornando-as dinâmicas, motivadoras e interessantes, promovendo uma aprendizagem realmente ativa. Entretanto, mesmo atualmente, ainda são muito pouco utilizados. E quando o são, nem sempre de forma dinâmica e contextualizada.

Entre as situações que dificultam o uso desses recursos, os profissionais entrevistados alertaram para os problemas com o uso do laboratório, como internet fraca e a pouca quantidade de computadores em funcionamento, pois a manutenção fornecida pela SEDUC-MT é programada diante da demanda de atendimento, podendo ser demorada.

De acordo com estudos de Gimenes e Araman (2019), a respeito de teses e de dissertações, que tratam da temática referente ao uso das Tecnologias da Informação e Comunicação no ensino de Matemática nos Programas de Pós-Graduação do Estado do Paraná, fica evidente que essa problemática não é uma característica específica da infraestrutura educacional mato-grossense. Segundo as autoras, suas pesquisas identificaram essas mesmas situações como dificuldades para o uso mais efetivo desses recursos pelos professores:

Outro pronto que faz com que os professores não utilizem as TDIC são os problemas técnicos que as máquinas apresentam e a falta de uma pessoa especializada para a manutenção destas. Os professores dizem que levam muito tempo para preparar os equipamentos para a aula, os computadores apresentam lentidão e, também, há muitas reclamações sobre a falta ou lentidão de acesso à internet. Estes problemas também dificultam o uso da TDIC na sala de aula (GIMENES; ARAMAN, 2019, p.46).

A questão do apoio técnico especializado para auxiliar os docentes também foi identificada, na presente pesquisa, como um fator que dificulta o acesso aos materiais. Os professores entrevistados citaram as incompatibilidades com os horários de funcionamento do laboratório, haja vista que há apenas um técnico contratado por $30 \mathrm{~h}$ para os dois períodos, tendo este que articular seus horários entre os dois turnos.

Essas são situações que precisam, evidentemente, ser superadas. No entanto, as justificativas denotam também uma limitação da concepção sobre o uso das tecnologias, associando o uso do computador apenas ao acesso à internet. A inserção de outros meios tecnológicos, como jogos digitais e programas, que podem ser utilizados de modo offline na falta de acesso à internet, não foram referenciados pelos pesquisados. Essa alternativa também seria uma oportunidade de os estudantes manterem contato com as diversas possibilidades de aprendizagem com as tecnologias, que podem ser associadas aos conteúdos escolares.

Marc Prensky (2018), como consultor educacional, 
destaca as características dessa nova geração de estudantes, que, segundo suas concepções, "precisam ser educados de forma diferente para o futuro". Nessa perspectiva, o autor evidencia a necessidade de o professor "inventar e experimentar" de acordo com as possibilidades de conexão e de apropriação de informações a que os alunos têm acesso atualmente. Ele defende, principalmente, a utilização de jogos digitais como recurso de interatividade interessante e atrativo aos estudantes.

Passos et al. (2020) identificaram, em suas pesquisas, a importância da aplicação de jogos digitais para alunos de cursos técnicos em informática. Embora o estudo tenha o foco em disciplinas específicas dos cursos, os autores evidenciam a articulação desses recursos, em sala de aula, como uma possibilidade positiva na integração entre metodologias de ensino e as tecnologias digitais:

Os resultados reforçam também a importância do uso das Tecnologias de Informação e Comunicação (TIC) em sala de aula, tirando da interação quadro e aluno da aula expositiva, e mostrando o potencial de aprendizagem quando são usados materiais que ao mesmo tempo sejam lúdicos e ensinem o aluno (PASSOS et al., 2020, p.115).

Nessa linha de pensamento, Prensky $(2010,2018)$ salienta a necessidade de que a escola integre o conhecimento formal com o conhecimento prático que o aluno precisa desenvolver, a posteriori, ao adentrar o mercado de trabalho. Para isso, é necessário que o uso das tecnologias seja direcionado em favor do aprendizado que o aluno pode desenvolver como protagonista, com a mediação do professor. Em suas assertivas, ele deixa evidente que a exposição dos conteúdos com uso das tecnologias não garante o suporte aos novos paradigmas de ensino, nos quais o papel da tecnologia é auxiliar os alunos a aprenderem e a ensinarem-se uns aos outros de forma colaborativa e autônoma.

Se conseguirmos concordar que o papel da tecnologia nas nossas salas de aula é o de apoiar a nova pedagogia a partir da qual os alunos ensinam a si mesmos com a orientação do professor, então poderemos nos movimentar muito mais rapidamente pela estrada que leva à obtenção dessa meta. No entanto, se cada pessoa continuar a falar sobre o papel da tecnologia de forma diferente, isso vai levar muito mais tempo para acontecer (PRENSKY, 2010, p.204).

O que Prensky defende, mais especificamente, quanto ao uso das tecnologias, é que seja delegado ao aluno o papel de investigador, instigado pela curiosidade sobre os benefícios que essas ferramentas podem proporcionar ao seu desenvolvimento. A Internet, conforme afirma Rodrigues (2019, p.176): "é, certamente, um dos meios de comunicação mais plurais, democráticos e multimidiáticos no mundo". Na perspectiva de sua utilização na aprendizagem, embora a infraestrutura digital na maioria das escolas públicas ainda seja carente de aprimoramento, acredita-se que existam formas de integração, a partir das relações que os próprios estudantes já estabelecem com essa tecnologia em seu contexto fora da escola.
As atividades interdisciplinares na perspectiva da inclusão digital, segundo o Projeto Político Pedagógico da escola lócus dessa investigação, envolvem:

Estudos de percentuais estatísticos sobre temas sociais relevantes, como o índice de violência contra as mulheres, articulando as disciplinas de matemática, língua portuguesa e a área de ciências sociais e humanas; vídeos sobre a cultura local e regional, envolvendo a área de linguagem, nas disciplinas de língua portuguesa, educação física e arte; área de ciências humanas e sociais, com as disciplinas de geografia e história (PPP, 2018, p. 238).

Essas atividades são desenvolvidas mais ao nível das datas comemorativas referentes aos temas, não sendo priorizadas durante todo o decorrer do ano letivo. A esse respeito, o próprio documento atenta para a necessidade de melhor orientação no sentido de aprimorar a relação e a articulação entre a prática pedagógica e a educação digital.

As iniciativas nesse sentido ainda são tímidas, considerando a evolução tecnológica e a disponibilidade de recursos e ferramentas digitais disponíveis no contexto desse universo. A proposta é que sejam desenvolvidos projetos que orientem a prática pedagógica no sentido de articular as tecnologias da informação e da comunicação aos saberes docentes já constituídos, na expectativa de aprimorar as experiências metodológicas, reestruturando as relações entre metodologias de ensino e o desenvolvimento da aprendizagem (PPP, 2018, p. 238).

Embora o discurso regimentado pelo Projeto Político Pedagógico da escola reflita uma concepção metodológica pautada em uma organização curricular, que ultrapasse os limites da sala de aula, enfatizando a construção do conhecimento como um processo dinâmico, articulado com a inovação tecnológica, as estratégias utilizadas parecem continuar priorizando uma metodologia de transmissão de conhecimento, com aulas expositivas e a predominância de exercícios repetitivos, sem as características do trabalho colaborativo, interdisciplinar e contextualizado.

Sabe-se que várias influências externas podem interferir no trabalho do educador, criando situações que venham a prejudicar o processo de ensino e aprendizagem. No entanto, as relações que o profissional estabelece com os educandos, seus procedimentos metodológicos e as formas de tratar os conteúdos curriculares podem contribuir, mais diretamente, para o sucesso ou, em contrapartida, criar um descompasso entre essas duas dimensões da educação. As ações educativas envolvem a contextualização entre sujeito, meio e objeto, devendo-se levar em consideração a articulação entre teoria e prática, entre as necessidades e expectativas dos envolvidos, ultrapassando os limites da reprodução e da transmissão de conteúdos e de conceitos prontos. Em uma era como a atual, caracterizada pelas inovações e pelo desenvolvimento tecnológico, é ainda mais imperativo que se promova a articulação entre as ações e os resultados almejados. Nessa perspectiva, a formação desses profissionais na dimensão dos avanços tecnológicos precisa ser pensada de maneira a garantir 
a construção dos saberes pedagógicos, de forma articulada, com os conhecimentos formais que o educando necessita apreender, levando em consideração as habilidades que os estudantes desenvolvem em suas experiências cotidianas com a tecnologia.

Conforme destacam Silva e Maciel (2020, p. 45), a análise do discurso de professores investigados, em escolas estaduais de Mato Grosso sobre a formação continuada, identificou a necessidade de o educador se posicionar como responsável principal, em seu aspecto formativo, assumindo “[...] a incumbência de compreender-se no desenvolver dessa formação continuada como personagem principal na construção de seus próprios saberes [...]".

Com a implementação do ProInfo e os projetos de estímulo ao uso pedagógico das tecnologias digitais, os Governos brasileiros, no decorrer das últimas décadas, têm investido na capacitação dos profissionais da educação e no equipamento das escolas com laboratórios de informática, internet e outros recursos. No entanto, essas medidas não serão suficientes se a modernização não alcançar a prática pedagógica em sala de aula. Para que isso ocorra, é imprescindível que as políticas educacionais voltem olhares mais abrangentes também para a dimensão formativa do professor, garantindo, tanto ao educador quanto ao educando, possibilidades de acesso aos conhecimentos sobre esses recursos.

De encontro a esse pensamento, em discussões sobre a Base Nacional Comum Curricular (BNCC), Maciel et al. (2017, p. 669) afirmam que:

Reitera-se que um documento da importância do BNCC exige mudanças de paradigmas em todos os sentidos e a formação de professores está em uma das urgências. Tais mudanças apontam simultaneamente para os professores (as) que já estão na sala de aula, a fim de que recebam uma formação continuada e os meios de desenvolvimento profissional necessários para assegurar que seus alunos (as) e a estrutura onde ocorrerá a aprendizagem estejam devidamente preparados para alcançar os novos padrões.

Comunga-se com a ideia de que a formação continuada nesse aspecto precisa contemplar os professores que estão atuando em sala. Os cursos sobre as TDCIs estão sendo ofertados pelo Governo e pelas Universidades já há algum tempo, porém a aplicabilidade, o manuseio dos materiais e a inclusão digital para o professor ainda é uma necessidade que precisa ser encarada pelo próprio docente como um desafio que deve ser superado.

O conceito de inovação sob uma perspectiva pedagógica evidencia a necessidade real de que os educadores assumam um compromisso com o processo educativo no sentido de produção e de assimilação crítica dessas inovações, segundo a concepção de Brito e Purificação (2011, p.37), o que implicará, conforme as autoras, "novos projetos fundamentados em concepções de ensinar e aprender diferentes das propostas já existentes". Sob esse enfoque, as transformações dependem também do interesse e da busca pela atualização que o docente desempenha durante seu processo formativo em serviço, adequando sua prática de acordo com a evolução que o desenvolvimento tecnológico proporciona.

Ampliando sua ideia, Brito e Purificação (2011, p. 37) advertem que apenas uma apropriação crítica de inovações de caráter pedagógico poderá "gerar mudanças que não sejam simples expressões da modernidade".

Nesse sentido, a formação continuada do profissional docente visa assegurar o desenvolvimento de competências que o habilitem, no contexto moderno, atualizar seus saberes iniciais e avaliar as mudanças necessárias para inovar suas práticas, atendendo aos reais imperativos e interesses da nova geração.

Durante este ano de 2020, o universo educacional viu-se, repentinamente, desarticulado de sua tradicional modalidade escolar em função de suspensão das aulas presenciais provocada pela pandemia que assola o Planeta, resultando no isolamento social obrigatório e necessário no atual cenário mundial.

As Secretarias de Educação passaram a disponibilizar atividades online via Ambiente Virtual de Aprendizagem para que os estudantes tenham acesso a materiais complementares

de aprendizagem. Alguns professores fazem vídeos com conteúdos explicativos, leitura e atividades que os estudantes podem desenvolver com a ajuda da família, disponibilizando o acesso pelas redes sociais, como o WhatsApp ou pelo

Microsoft Teams, aplicativo disponibilizado pela SEDUCMT para que os professores possam interagir virtualmente

com seus alunos. Essas medidas visam, de certa forma, a continuidade do processo de aprendizagem dos alunos, embora nem todos tenham acesso a esses meios. Para os alunos, que não possuem, estão sendo disponibilizados materiais impressos com os conteúdos e as atividades complementares.

$\mathrm{O}$ evento que provocou o isolamento social e, consequentemente, o afastamento de professores e alunos de seu ambiente habitual de estudo, também desencadeou a procura por novas formas de gerir a aprendizagem e que

suprissem as necessidades emergenciais nesse contexto excepcional, na perspectiva de minimizar os prejuízos com o ensino e garantir o direito à continuidade da escolarização. Neste cenário, o uso das Tecnologias Digitais de Informação e Comunicação se apresentaram como alternativa e o mundo virtual passou a ser a nova sala de aula.

Embora a maioria dos professores utilize apenas a apostila como referência de atividades para as aulas, a qualidade desse material tem melhorado, consideravelmente, com inclusão de links para acesso a vídeos ou textos com conteúdo complementar ao tema discutido. Além disso, vários professores já desenvolveram novas técnicas para disponibilização do material das aulas online, com a gravação de videoaulas explicativas, utilizando, inclusive, as apresentações do PowerPoint com os recursos de imagens e de animação.

Não há como prever o retorno das aulas presenciais diante da instabilidade quanto à propagação dos efeitos da Pandemia, 
porém este é um período significativo quanto ao avanço na utilização desses recursos educacionais. Conforme discorre Rodrigues (2019, p. 179): "as transformações ocorridas na sociedade nas últimas décadas, inegavelmente, alcançam a educação e obrigam os atores a uma adaptação nas formas de ensino".

A partir dessa experiência, tanto professores quanto estudantes podem descobrir novas e não tradicionais metodologias de ensino e de aprendizagem. Enquanto o aluno aprende que o universo tecnológico dispõe de recursos, que podem potencializar suas descobertas e promover sua autonomia diante da busca pelo conhecimento, o professor descobre que pode aprender ao mesmo tempo em que ensina e que a restrição do conhecimento ao simples repasse de conteúdos programados, entre quatro paredes, não será suficiente frente aos desafios dessa nova era.

\section{Conclusão}

As reflexões postuladas e os dados analisados ressaltam a necessidade da adoção de um paradigma de educação centrado no educando, compatível com os avanços nas áreas tecnológicas e científicas do conhecimento. Não basta, entretanto, a escola adquirir recursos modernos se não os utilizar para reavaliar seus conceitos de ensino e aprendizagem, buscando uma concepção de educação inovadora e significativa, pautada na construção do conhecimento e não apenas na transmissão de informações.

Esse estudo objetivou proporcionar oportunidades de reflexão sobre o uso das mídias digitais e das tecnologias da informação na metodologia de ensino aplicadas pelos profissionais investigados, constatando-se que o mundo virtual e os recursos digitais ainda são um desafio a ser superado pelos professores formados a partir de uma concepção tradicional, baseada na cultura do papel e de equipamentos e recursos analógicos.

A pesquisa evidenciou, ainda, a falta de infraestrutura nas escolas que facilitem a inserção desses profissionais e estudantes no universo digital, garantindo o apoio técnico necessário e o acesso a equipamentos e internet de qualidade. Entretanto, as discussões destacam também a necessidade de que o professor busque formação no sentido de aprimorar sua metodologia diante das inovações tecnológicas que se apresentam no cenário atual, posicionando-se como responsável principal pelo desenvolvimento do seu ofício.

A utilização de multimeios digitais, como a Internet, som, imagens estáticas e dinâmicas, vídeos, possibilita trazer para a sala de aula as ferramentas que já fazem parte, de alguma forma, da vida dos estudantes.

Destarte, a mediação pedagógica, nesse sentido, precisa levar em conta as necessidades do educando, valorizando suas habilidades e os meios dos quais ele mais se apropria e se identifica para produzir seu próprio conhecimento. $\mathrm{O}$ professor, dando vez e voz ao seu aluno, cumpre seu papel de mediador desse processo, não apenas como um colaborador, mas também como um facilitador, capaz de estimular a curiosidade, o questionamento, o debate e o intercâmbio de informações que realmente produzam conhecimentos novos. O aluno, ao eleger e discutir conteúdos, metodologias e recursos que considera essenciais ao seu crescimento, assume seu compromisso com o desenvolvimento próprio e o seu papel de protagonista na aprendizagem.

Diante das transformações que os últimos acontecimentos vêm emprestando às formas de comunicação e relacionamentos, à economia e à política educacional, a escola não poderá manter-se alheia ao importante e fundamental papel das Tecnologias Digitais da Informação e da Comunicação na educação contemporânea. Aulas online não substituem o valor presencial do professor, porém os conceitos metodológicos e as relações que envolvem a prática pedagógica estão a cada dia sendo reestruturados, renovados e reconstruídos pela comunidade educacional diante da inovação. Quem não acompanhar corre o risco de ficar pelo caminho.

Portanto, espera-se que este estudo possa contribuir para uma investigação mais aprofundada quanto ao uso desses recursos na Educação, especialmente, na perspectiva dos estudantes, garantindo sua participação efetiva nos debates sobre o uso dessas ferramentas como recurso educacional.

\section{Referências}

ANDRÉ, M.E.D.A. Etnografia da prática escolar. São Paulo: Papirus, 2013.

BRITO, G.S.; PURIFICAÇÃO, I. Educação e novas tecnologias: um (re)pensar. Curitiba: IBPEX, 2011.

BRUZZI, D.G. Uso da tecnologia na educação, da história à realidade atual. Polyphonía UFG, v.27, n1, p.475-483, 2016.

CARDOSO, A.O.C. Tecnologias digitais, currículo e interdisciplinaridade na escola: um link possível a partir da ação docente. Educ. Por Escrito, v.6, n.2, p.208-219, 2015.

CORTELLA, M.S. Educação, escola e docência: novos tempos, novas atitudes. São Paulo; Cortez, 2014.

COSTA, L.M. Programa Nacional de Tecnologia Educacional. (ProInfo) - Expansão, democratização e inserção das tecnologias na Rede Pública. Quanta Com. Cultura, v.1, n.1, p.52-63, 2015.

ESCOLA ESTADUAL PROF. a ALICE FONTES PINHEIRO, Projeto Político Pedagógico 2018, Cuiabá, 2018.

FLICK, U. Introdução à pesquisa qualitativa. Porto Alegre: Artmed, 2009.

GIL, A.C. Métodos e técnicas de pesquisa social. São Paulo: Atlas, 2019.

GIRAFFA, L.M.M. Jornada nas escolas: a nova geração de professores e alunos. Tecnol. Soc. Conhecimento, v.1, n.1, p.100$118,2013$.

KENSKI, V.M. Educação e tecnologias: um novo ritmo da informação. Campinas: Papirus, 2012.

LAGO, C.F. A tecnologia utilizada na educação pelos padres jesuítas no Brasil colonial. 2012. Disponível em: http://www. celso.lago.nom.br/tcc-me-celso-frederico-lago\%20-\%20FINAL. pdf. Acesso em 26 abr. 2020.

LAKATOS, E.M.; MARCONI, M.A. Fundamentos de 
metodologia científica. São Paulo: Atlas, 2017.

MACIEL, C.M.L.A. et. al. Visão de professores de escolas de Cuiabá/MT e Campo Verde/MT sobre a Base Nacional Comum Curricular (BNCC). Rev. Educ. Pública, 2017. Disponível em http://periodicoscientificos.ufmt.br/ojs/index.php/ educacaopublica. Acesso em 18 abr. 2020.

MINAYO, M.C.S. (Org.). Pesquisa Social. Teoria, método e criatividade. Petrópolis: Vozes, 2014.

MORAN, J.M. Novas tecnologias e o reencantamento do mundo. 1995. Disponível em: http://www.eca.usp.br/prof/moran/site/ textos/tecnologias.pdf - Acesso em: 5 abr. 2020.

MORAN, J.M. Desafios que as tecnologias digitais nos trazem. 2013. Disponível em: http://www.eca.usp.br/prof/moran/site/ textos/tecnologias_eduacacao/desaf_int.pdf. Acesso em: 30 out. 2020 .

NÓVOA, A. Formação de professores e trabalho pedagógico. Lisboa: Educa, 2002.

PERRENOUD, P. A prática reflexiva no ofício de professor: profissionalização e razão pedagógica. Porto Alegre: Artmed, 2002.

PIAGET, J. A construção do real na criança. São Paulo: Ática, 2001.

PRENSKY, M. O aluno virou especialista. Rev. Época. 2010. Disponível em: http://revistaepoca.globo.com/Revista/ Epoca/0,,EMI153918-15224,00. Acesso em: 12 ago. 2020.
PRENSKY, M. Não podemos forçar os jovens a fazer o que foi bom para nós. Rev. Eletr. Consultor Jurídico, 2018. Disponível em: https://www.conjur.com.br/2018-jan-02/embargadamilenio-marc-prenskyconsultor-educacao. Acesso em: 10 set. 2020.

QUEIROZ, D.R. et. al. Saberes docentes nas décadas de 70 e 80. Cad. Fucamp, v.14, n.21, p.15-29, 2015.

RODRIGUES, A.C.L. Processos de aprendizagem: o auxílio das mídias digitais e a realização da prática de Stop Motion em sala de aula. Rev. Ensino Educ. Ciênc. Hum., v.20, n.2, p.170-180, 2019. doi: https://doi.org/10.17921/2447-8733.2019v20n2p170-180

SANTOS, P.K. Opedagogo em multimeios e informática educativa e sua contribuição para a eficácia da utilização das tecnologias de informação e comunicação na educação. 2006. Disponível em http://www.abed.org.br/seminario2006/pdf/tc036.pdf. Acesso em: 10 abr. 2020.

SAVIANI, D. Educação: do senso comum à consciência filosófica. São Paulo: Cortez, 1981.

SILVA, J.G.; MACIEL, C.M.A. O discurso dos professores sobre a formação continuada em suas respectivas áreas do conhecimento. Rev. Ensino Educ. Ciênc. Hum., v.21, n.1, p.40-46, 2020. doi: https://doi.org/10.17921/2447-8733.2020v21n1p40-46

SOARES, R.S.; FAÇANHA, A.A.B.; CARDOSO, F.H.A.

Utilização das tecnologias de informação e comunicação no ensino de ciências: estudo de caso em uma escola particular de TeresinaPI. Rev. Ensino, Educ. Ciênc. Hum., v.10, n.1, p.110-117, 2019. doi: https://doi.org/10.17921/2447-8733.2019v20n1p110-117 